\title{
WV Dental Hygienists' Knowledge and Educational Approach for Pregnant Women
}

\author{
Isabella Hope McDaniel \\ inmcdaniel@mix.wvu.edu
}

Follow this and additional works at: https://researchrepository.wvu.edu/etd

Part of the Dental Hygiene Commons

\section{Recommended Citation}

McDaniel, Isabella Hope, "WV Dental Hygienists' Knowledge and Educational Approach for Pregnant Women" (2020). Graduate Theses, Dissertations, and Problem Reports. 7911.

https://researchrepository.wvu.edu/etd/7911

This Thesis is protected by copyright and/or related rights. It has been brought to you by the The Research Repository @ WVU with permission from the rights-holder(s). You are free to use this Thesis in any way that is permitted by the copyright and related rights legislation that applies to your use. For other uses you must obtain permission from the rights-holder(s) directly, unless additional rights are indicated by a Creative Commons license in the record and/ or on the work itself. This Thesis has been accepted for inclusion in WVU Graduate Theses, Dissertations, and Problem Reports collection by an authorized administrator of The Research Repository @ WVU. For more information, please contact researchrepository@mail.wvu.edu. 
Graduate Theses, Dissertations, and Problem Reports

2020

WV Dental Hygienists' Knowledge and Educational Approach for Pregnant Women

Isabella Hope McDaniel

Follow this and additional works at: https://researchrepository.wvu.edu/etd

Part of the Dental Hygiene Commons 
Isabella H. McDaniel, RDH, BSDH

\author{
Thesis submitted to the \\ School of Dentistry \\ at West Virginia University \\ in partial fulfillment of the requirements \\ for the degree of \\ Master of Science \\ in \\ Dental Hygiene
}

\begin{abstract}
Alcinda Trickett-Shockey, DHSc, MA, BSDH, RDH, CHS-IV, CTTS, CNTA, Chair
R. Constance Wiener, DMD, PhD

Ashlee Sowards, RDH, MSDH, TTS

Department of Dental Hygiene
\end{abstract}

Morgantown, West Virginia

2020

Key Words: pregnant women, oral hygiene instruction, dental prophylaxis, registered dental hygienist

Copyright 2020 Isabella H. McDaniel 


\section{ABSTRACT \\ WV Dental Hygienists' Knowledge and Educational Approach for Pregnant Women Isabella H. McDaniel, RDH, BSDH}

Background: Adverse pregnancy outcomes have become a concern for dental professionals caring for pregnant women with poor oral health. Pregnant women may not be aware of their increased risk of bacterial infections in their oral tissues and how it could relate to adverse pregnancy outcomes such as pre- term birth (PTB) and low birthweight babies (LBW). Dental healthcare professionals need to be well informed of risk related to poor oral health and have confidence to effectively educate pregnant women. PTB and LBW babies account for 1 million infant deaths annually. It is the responsibility of dental healthcare professionals to be well informed of risks associated with periodontal disease to adequately educate pregnant patients.

Purpose: The purpose of this study is to assess licensed West Virginia dental hygienists' knowledge and educational approaches for pregnant women to determine if there is a need for continuing education (CE) course(s) related to educating pregnant women about oral healthcare during pregnancy.

Methods: A survey was provided to licensed dental hygienists addressing their personal knowledge, confidence, and feelings regarding: pregnant women's oral health; the average number of pregnant women seen within a month; the time allotted for a routine prophylaxis for pregnant women; the use of American Dental Association (ADA) codes D1330 "Oral Hygiene Instruction" and D4346 "Scaling in the Presence of Moderate to Severe Gingival Inflammation"; their highest level of education; the number of years as a registered dental hygienist (RDH); and, the region of West Virginia in which they practice.

Results: The results of this study reveal current practicing dental hygienists in West Virginia are knowledgeable on how pregnancy affects women's oral health and the associated risks. However, dental hygienists who have been practicing for greater than 10 years are more confident when educating pregnant patients.

Conclusion: As a continuing education needs assessment project, the researcher of this study indicates a need for dental hygienists who have been practicing for less than 10 years to participant in confidence building activities so they can better educate pregnant patients. 


\section{ACKNOWLEDGEMENTS}

I would like to extend a personal thank you to everyone who helped make my research possible.

Dr. Alcinda K. Trickett-Shockey, thesis committee chair, for her guidance throughout my research. Also, for believing in me as I assisted in teaching the undergraduate students as a graduate assistant (GA).

Dr. R. Constance Wiener, thesis committee member, for her expertise and willingness to be a part of my committee.

Ms. Ashlee Sowards, thesis committee member, for her support and encouragement throughout my dental hygiene education.

Mrs. Amy Funk, advisor, for many years of guidance and uplifting support throughout my dental hygiene education.

Dr. Jonathan R. Pyle, for all his love and constant support throughout my entire education. Also, for providing me with a fun work environment during this journey.

Mrs. Kaitlyn McQuain, RDH, classmate and cherished friend, for her being my rock during this chapter of our lives and always finding the time to send love and encouragement my way.

Mrs. Kristi Vance, RDH, coworker and friend, for helping me grow and gain confidence as a hygienist. 


\section{TABLE OF CONTENTS}

$\underline{\text { Page }}$

TITLE

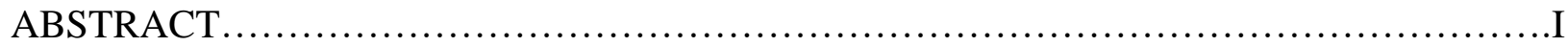

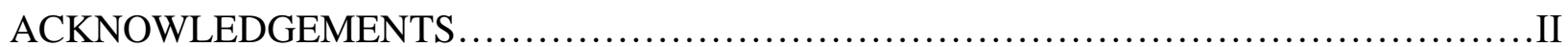

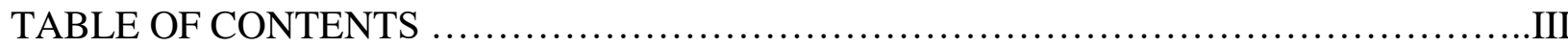

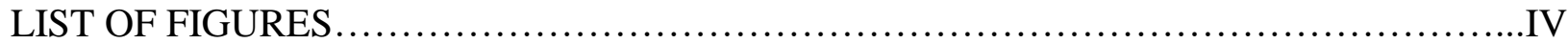

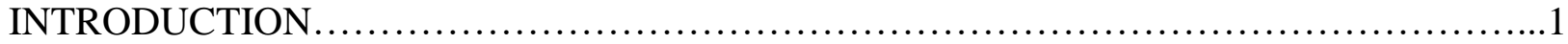

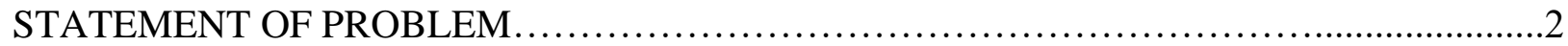

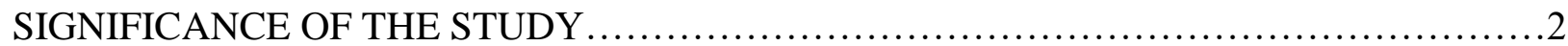

LITERATURE REVIEW .......................................................... 3

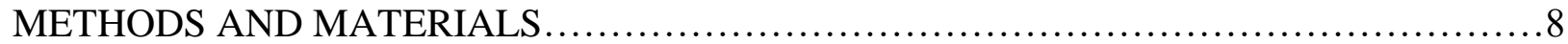

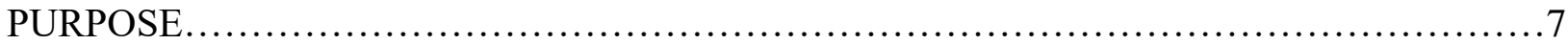

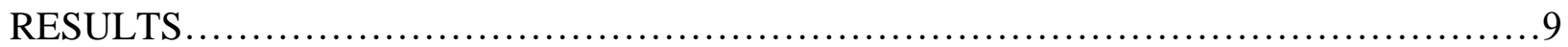

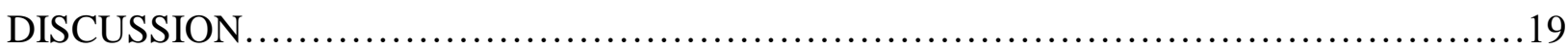

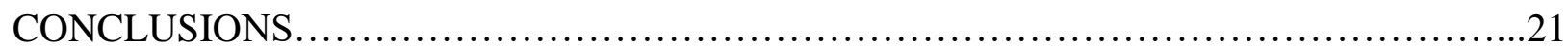

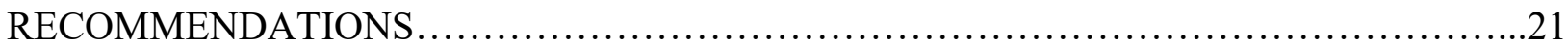

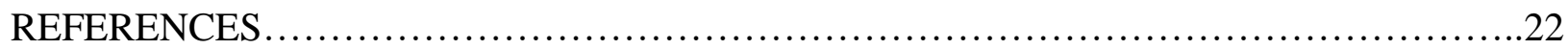

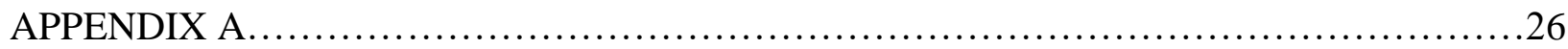

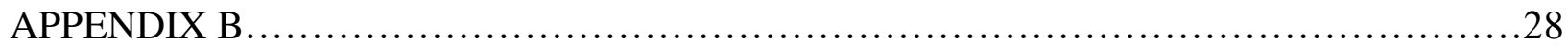

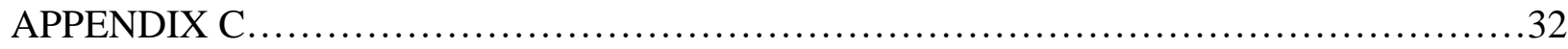

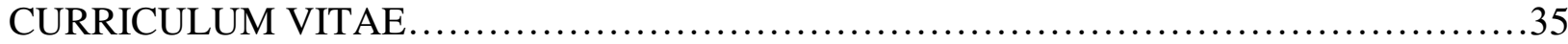


LIST OF FIGURES AND TABLES

\begin{tabular}{|c|c|c|c|}
\hline Title & Figure & Table & Page \\
\hline Regions of West Virginia Dental Hygienists' Currently Practice & 1 & & 9 \\
\hline Type of Practice Dental Hygienists' Currently Practice & 2 & & 10 \\
\hline Dental Hygienists' Highest Level of Education & 3 & & 10 \\
\hline Dental Hygienists' Feels Adequately Educated and Comfortable Educating & 4 & & 11 \\
\hline Dental Hygienists' Perception of Patient's Knowledge & 5 & & 12 \\
\hline Number of Pregnant Patients Seen in a Month & 6 & & 13 \\
\hline Minutes Allotted for Routine Prophylaxis for Pregnant Women & 7 & & 13 \\
\hline Dental Hygienists' Feel Additional Time is Needed for Patient Women & 8 & & 14 \\
\hline Amount of Additional Treatment Time Dental Hygienists' Feel is Needed & 9 & & 14 \\
\hline Dental Hygienists' Re-appoint Pregnant Women for Counseling & 10 & & 14 \\
\hline Comparison of Knowledge for the Groups of Dental Hygienists & 11 & & 15 \\
\hline $\begin{array}{l}\text { Chi-Square Test: Comparison for the Groups of Dental Hygienists } \\
\text { Knowledge }\end{array}$ & & 1 & 15 \\
\hline Comparison of Confidence for the Groups of Dental Hygienists & 12 & & 16 \\
\hline $\begin{array}{l}\text { Chi-Square Test: Comparison of the Groups of Dental Hygienist } \\
\text { Confidence }\end{array}$ & & 2 & 16 \\
\hline Comparison of Self-Perceived Confidence of Pregnancy Gingivitis & 13 & & 17 \\
\hline $\begin{array}{l}\text { Table 3: Chi-Square Tests: Significance for Comparison of Self-Perceived } \\
\text { Confidence of Pregnancy Gingivitis }\end{array}$ & & 3 & 17 \\
\hline $\begin{array}{l}\text { Comparison of Self-Perceived Confidence of Preterm Birth and Low } \\
\text { Birthweight (PTB_LBW) }\end{array}$ & 14 & & 18 \\
\hline $\begin{array}{l}\text { Chi-Square Test: Comparison of Self-Perceived Confidence of Preterm } \\
\text { Birth and Low Birthweight (PTB_LBW) }\end{array}$ & & 4 & 18 \\
\hline
\end{tabular}




\section{INTRODUCTION}

Adverse pregnancy outcomes including preterm birth (PTB) and low birth weight (LBW) babies are increasing (WHO, 2020). According to the Center for Disease Control and Prevention (CDC), in the United States in 2018, 1 in 10 babies were born before 37 weeks of gestational, the criteria for PTB. PTB are at an increased risk of death or serious disabilities (CDC, 2019). Globally, PTB complications account for approximately 1 million infant deaths each year. PTB is postulated as the leading cause of death in children under the age 5 years old (WHO, 2020).

Pregnant women with active periodontal diseases have been studied to evaluate the association of PTB and LBW babies with active, uncontrolled periodontal disease. Pregnant women may be at a disadvantage for gingivitis due to exaggerated dental plaque biofilm and hormonal changes during their second and third trimester (Gehrig \& Willmann, 2008). The CDC states pregnant women are $60-75 \%$ more likely to experience gingivitis during their pregnancy (CDC, 2019).

The level of periodontal disease (loss of bone supporting a teeth or teeth) in the population of adults ages 30 years and above is $47.2 \%$ (CDC, 2019). Azofeifa, et al. reported the prevalence of periodontal disease in pregnant women was estimated it be $3.1 \%$ among pregnant women in their sample of 847 pregnant women (2016).

Dental hygienists need to be knowledgeable about the risk associated with poor oral health during pregnancy in order to confidently educate their pregnant patients. Pregnant women must be aware of how their oral health will affect their developing child. It could potentially reduce the risk of adverse pregnancy outcomes associated with periodontal disease if dental hygienists provided education to pregnant women during routine dental prophylaxis appointments.

In a small, preliminary study conducted by this researcher, West Virginia women indicated that during their pregnancy/pregnancies, they did not recall receiving oral health information from their dental hygienists. This researcher was interested in determining if there was indeed a lack of information being presented to pregnant women. It should be noted that much of the research concerning PTB and LBW babies was conducted and disseminated primarily within the previous decade. It is possible that dental hygienists who had graduated prior to 2010 were unaware of the association and in fact do not provide such education. It is also possible that there are other factor influencing the provision of such education. 


\section{STATEMENT OF THE PROBLEM}

It is unknown if dental hygienists are adequately informing pregnant women on the potential increased risks of adverse pregnancy outcomes in patients with periodontal disease(s) due to having graduated from dental programs prior to the time in which much of the research was completed. The primary null hypothesis is licensed West Virginia dental hygienists who graduated before 2010 are as likely as dental hygienist who graduated between 2010-2020 in their self-perceived knowledge about oral health during pregnancy.

The secondary null hypothesis is there is no difference between licensed West Virginia dental hygienists who are confident in providing oral health education to pregnant women between those who graduated before 2010 and those who graduated between 2010-2020.

\section{SIGNIFICANCE OF THE STUDY}

Pregnant women are 60-75\% more likely to experience the periodontal disease, gingivitis, during their pregnancy then non-pregnant women (CDC, 2019). Pregnancy gingivitis is a reversible bacterial infection localized to the gingiva related to an increase in dental plaque biofilm and hormonal changes during pregnancy (Gehrig \& Willmann, 2008). Although gingivitis does not necessarily progress to involve supporting structures it is important to disrupt the plaque accumulated around teeth, especially for pregnant women. It should be noted these are controversies. One author reported that pregnant women are mother likely to have to gingival inflammation (Murakami, et al., 2018); however, other researchers reported that the clinical features are the same as classical gingivitis and there may be no difference in gingival health between patients who are pregnant or not if they maintain good plaque control (Moreli, et al., 2018). "Gingivitis does not always develop into periodontal disease." (Mann, et al., 2019). However, if periodontal disease does occur, there is destruction of the supporting structures of the periodontium including the gingiva, periodontal ligament (PDL), bone, and cementum (Gehrig \& Willmann, 2008). Periodontal disease during pregnancy has a tentative association with adverse pregnancy outcomes such as preterm birth (PTB) and low birthweight (LBW) babies. Of adults aged 30 years and older $47.2 \%$ have some form of periodontal disease ( CDC, 2019). The American Academy of Periodontology recommends that pregnant women should maintain a healthy lifestyle and good periodontal health (AAP, 2020). During gestation, weeks $37-40$ are the weeks in which the lungs, brain, and nervous system are continuing to develop 
(ACOG, 2020). Babies that are born before the 37-week gestational period are at an increased risk of death before the age of 5 years old and/or serve long-term disability issues (CDC, 2019; WHO, 2020).

Premature birth has been increasing over the past few years globally. There has been a 10\% increase being in the United States between 2015 and 2018 (CDC, 2019). Although, the research only suggests an association between periodontal disease and adverse pregnancy outcomes dental healthcare professionals need remain current in their knowledge and provide current information to their pregnant patients.

Secondarily, pregnant patients often present more complex treatment needs than nonpregnant patients. Dental hygienists need adequate time in their schedule to meet such needs. Many dental hygienists (65\%) reported being stressed by not having enough time in their work schedule in general (Barnard, et al., 2020). It is unknown as to how this relates to caring for patient patients.

\section{LITERATURE REVIEW}

Recent events in which dental practices were closed due to SARS-COV-2 have increased the public's anxiety about seeking routine dental care. Although by May 2020, public health officials indicated that dental care was an essential service, many people were hesitant to return. This is particularly true of pregnant women who had received mixed messages about dental care before SAR-COV-2. Dental hygienists need to be comfortable, current, and accurate in their educational approaches to pregnant women. Listed below are examples of questions that are frequently posed on Google by pregnant women:

Should I see a dentist while pregnant?

Is it safe to have a dental cleaning for me and my baby, or should I wait?

Is it safe to have radiographs for a tooth that is bothering me, or should I wait?

The tissue around my teeth is red and very tender. What should I do?

I have never had a problem with my appointments; I come every 6 months, but now that I am pregnant, I have this large bulge on my tissue. What should I do? 
I have never had a problem with my appointments; I come every 6 months, but I read that all pregnant women should have scaling and root planing to prevent pre-term birth. Is that true?

Dental hygienists need to know the current literature for discussing the concerns and answering frequent questions many pregnant women have involving their oral health during their pregnancy. Topics dental hygienists should be very familiar with are: pregnancy gingivitis, periodontal disease treatments, caries treatment during pregnancy, safety of care, patient comfort, dietary issues, oral hygiene (including after morning sickness), and the associations of periodontitis and adverse pregnancy outcome.

\section{Periodontal Disease: Gingivitis}

Gingivitis is a periodontal disease usually involving inflammation as a result of an immune response of the gingiva to dental plaque biofilm. Often, the gingiva clinically becomes red, swollen, and very tender with increased bleeding (Nield-Gehrig \& Willmann, 2011). Gingivitis is a reversible form of periodontal disease with professional treatment and good oral health home care (AAP, 2019). The American Academy of Periodontology acknowledges gingivitis represents a spectrum of diseases that are not limited only to plaque-related bacteria, but also systematic diseases including: diabetes, leukemia, endocrine changes (puberty, pregnancy), medications, and malnutrition (AAP, 2000).

It is important for dental hygienists to remain current, comfortable, and accurate on their recommendations for caring for patients with periodontal diseases, especially pregnant women and patients with other systemic diseases that affect their oral health. Pregnant women are at a $60-75 \%$ higher risk of experiencing what is known as pregnancy gingivitis, particularly during their second and third trimesters when estradiol, estriol, and progesterone increase (Williams \& Wilkin, 2011; CDC, 2019). Pregnant patients are commonly uncertain of the cause of changes in their oral health and the safety of continuing routine preventative dental treatment(s) and radiographs. The gingival tissues of pregnant women are impacted by hormonal changes during pregnancy. It often becomes thinner, more permeable, and tender (Williams \& Wilkin, 2011; ADA, 2019). In some cases, the gingival papilla reacts strongly to the bacteria associated with dental plaque biofilm causing a large, overgrowth of gingival tissues known as a pyogenic granuloma or a "pregnancy tumor" (Nield-Gehrig \& Willmann, 2011). A meta-analysis using 
5,935 participants investigated available evidence of the prevalence and characteristics of oral mucosal disorders among pregnant women (Melo, et al, 2019). It was reported that $17.1 \%$ of the pregnant participants experienced gingival hyperplasia and 3\% experienced a pyogenic granuloma (Melo, et al, 2019).

\section{Periodontal Disease: Periodontitis}

Periodontitis is defined as an inflammatory disease that affects the soft and hard structures which support teeth (AAP, 2019). When periodontitis occurs, there is an increase in the release of the inflammatory mediators, known as cytokines, causing destruction to supporting structures around a tooth or teeth leading to gingivitis or periodontitis (Davenport, et, 2010). Often, when plaque-induced gingivitis is left untreated it progresses into chronic periodontitis (Williams \& Wilkins, 2011). This happens due to the release of cytokines as an immune response in the presence of a bacterial infection, which over time potentially initiates the destruction of the bone (Williams \& Wilkins, 2011).

In the United States an estimated $47.2 \%$ of adults have mild, moderate, or severe periodontitis (CDC, 2013; AAP, 2012). The Center for Disease Control and Prevention reported: periodontitis is more common in men than women (56.4\% vs. $38.4 \%)$; those living in federal poverty level (65.4\%); those with less than a high school education (66.9\%); and current smokers $(64.2 \%)$.

\section{Dental Radiographs:}

Dental hygienists need to be able to explain the safety of having radiographs and other dental treatment(s) completed pregnancy. Dental radiographs are reported to be safe and necessary to perform throughout pregnancy to help diagnose infections and carious lesions (APA, 2017). Most radiographs when completed on arms, legs, head, teeth, or chest do not expose reproductive organs directly to the x-ray beam, which does not cause any harm to the developing child (FDA, 2017). Pregnant patients have the right to refuse the recommended radiographs. Dental hygienists must be knowledgeable in order to explain to the pregnant patient, not only the risk of periodontal disease, but the increase risk of dental caries and erosion throughout the pregnancy to help pregnant patients understand the necessity of these procedures (ADA, 2019). 


\section{$\underline{\text { Adverse Pregnancy Outcomes: Pre-term Birth and Low Birth Weight }}$}

The World Health Organization defines preterm birth as, “ babies born alive before 37 weeks of pregnancy are completed" (2018). In the United States from 2015 to $2018,10 \%$ of babies were born prematurely (CDC, 2019). Globally approximately $11 \%$ of babies were born prematurely (WHO, 2018). In lower income countries $12 \%$ of babies are born prematurely (WHO, 2018). Approximately two-thirds of premature births occurred without evident risk factors (Vogel, et al, 2018).

\section{$\underline{\text { Adverse Pregnancy Outcomes and Periodontitis }}$}

The association of adverse pregnancy outcomes and periodontal disease is not fully understood and needs further investigation (CDC, 2019). There are other significant known risk factors that confound the association of periodontal disease and adverse pregnancy outcomes such as: maternal age, ethnicity, social class, education, socioeconomics, nutrition, illness, gramnegative anaerobic microorganisms, and smoking (Davenport, et, 2010).

In a systematic review of 20 randomized controlled trials involving 8,171 pregnant participants where nonsurgical periodontal treatment was completed, there was a significant decrease in the risks of perinatal mortality (Wei Guang, et al, 2019). This study also reported periodontal treatment during pregnancy did not have an association with other adverse pregnancy outcomes such as: preeclampsia, gestational diabetes, cesarean sections, small for gestational age, or congenital malformations (Wei Guang, et al, 2019). A few other researchers with randomized studies investigated pregnant women with periodontal disease to evaluate the effectiveness of completing nonsurgical periodontal therapy to reduce the likelihood of PTB. These studies revealed that nonsurgical periodontal therapy during the second trimester did not reduce the risk of PTB (Boggess, 2020). Some researchers have suggested completing nonsurgical periodontal therapy in the second to third trimester might be too late to be effective for reducing adverse pregnancy outcomes (Boggess, 2020 \& Yiorgos et al, 2020).

Oral Hygiene Instructions:

Dental hygienists need to encourage pregnant patients to continue routine preventative treatment, as it highly recommended to help reduce the possibility of periodontal infections (APA, 2012). It is important for dental hygienists to instruct their pregnant patients about the 
proper techniques for maintaining oral health. Regular brushing and flossing techniques should be reviewed with pregnant patients and greatly encouraged by the dental hygienist to decrease the amount of dental plaque biofilm that might worsen gingival inflammation, redness, tenderness, and bleeding.

Another topic dental hygienist needs to educate pregnant patients about is tooth erosion, as it is a concern for pregnant women during the early stages of pregnancy. It has been recommended pregnant women avoid brushing immediately after emisis and use a sodium bicarinate mouth rinse to neutralize acid and prevent damage to the enamel (ADA, 2019). Depending upon the patient's caries risk, dental hygienists should also encourage their pregnant patients to have fluoride varnish applied after routine preventative appointments to help prevent damage to the tooth and sensitivity (Giglio, et al, 2009).

\section{Conclusion}

It can be concluded based on the reviewed literature the importance for dental hygienists to be comfortable, current, and accurate about current information related to oral health and pregnant women. Dental hygienists need to be aware and current about these potential risks of poor oral health as well as techniques related to the maintenance of oral health. Pregnant patients trust that dental hygienists will provide information and recommendations to maintain a healthy lifestyle and good oral health during their pregnancy. If dental hygienists do not feel comfortable and confident providing pregnant women with oral health education and the possible associated risks related to periodontal diseases, then it may be a need for additional education (continuing education) or to intensify the education of dental hygiene students.

\section{PURPOSE}

This study had two aims:

1) To determine if there was a greater need for continuing education for dental hygienists who had graduated within the previous ten years versus the dental hygienists who had graduated more than ten years ago based upon knowledge;

2) To determine if there was a greater need for developing confidence in providing education to pregnant women, comparing dental hygienists who had graduated within the 
previous ten years versus the dental hygienists who had graduated more than ten years ago based upon their self-reports of confidence.

\section{METHODS AND MATERIALS}

\section{Ethical Statement}

This study was approved by the West Virginia University Institutional Review Board. The approval number was 1912821062R001. (Appendix A)

\section{Study design}

This was a cross-sectional observational study.

\section{Study Sample}

Licensed West Virginia dental hygienists were recruited.

A one-time survey and cover letter were e-mailed to 976 West Virginia dental hygienists concerning their knowledge and confidence in sharing that knowledge concerning pregnancy and oral health (Appendix B and C). "Study data were collected and managed using REDCap electronic data capture tools hosted at West Virginia University REDCap (Research Electronic Data Capture) is a secure, web-based software platform designed to support data capture for research studies, providing 1) an intuitive interface for validated data capture; 2) audit trails for tracking data manipulation and export procedures; 3 ) automated export procedures for seamless data downloads to common statistical packages; and 4) procedures for data integration and interoperability with external sources. (Harris, et al., 2009). There were 21 multiple choice items.

Within the survey were there selection including:

1) the dental hygienists' knowledge and confidence for educating pregnant women;

2) the dental hygienists' current approaches for pregnant women during routinely dental prophylaxis; and,

3) the dental hygienists' demographics.

\section{Measures}

Knowledge and confidence questions on the survey were developed with Likert-style options. Dental hygienists were categorized based on the time since their graduation (within the previous 10 years or $>10$ years). The year, 2010, was selected as a critical year. Healthy People 2020 goals were established in 2010 for efforts to decrease pre-term deaths from 6.6 per 1000 live births (in 2005) to 5.9 per 1000 live births in 2020 (HealthyPeople, 2010). There was an urgent and strong, public health incentive to educate dental hygiene students and practicing 
hygienists (through continuing education) about the health of pregnant women as it was associated with infant health at that time.

Participants responded to the email recruitment by following a hyperlink to a West Virginia University secure data collection system (REDCAP) where the data were housed.

\section{Statistical analysis}

Data were analyzed for frequency of responses (percentages) and descriptive statistics using the internal REDCAP system. The knowledge variable, and confidence variable (initially Likert-like scores) were dichotomized with 1) strongly agree and agree as one category and 2) strongly disagree, disagree, and neutral as the second category. Data were analyzed for bivariate analysis with IBM SPSS version 26.

\section{$\underline{\text { RESULTS }}$}

There were 976 surveys mailed and 122 returned (response rate, 12.5\%). Six (0.6\%) were returned as invalid due to an inactive license or currently a nonpracticing dental hygienist in West Virginia.

All nine regions of West Virginia were represented in this study. There were $35.8 \%$ of respondent from Mountaineer Country; 8.3\% Northern Panhandle; 8.3\% Eastern Panhandle; 3.3\% Potomac Highlands; 2.5\% Mountain Lakes; 13.3\% New River/Greenbrier Valley; 2.5\% Hatfield-McCoy Mountains; 18.3\% Metro Valley; and 7.5\% Mid-Ohio Valley (Figure1).

Figure 1: Regions of West Virginia Dental Hygienist Current Practice

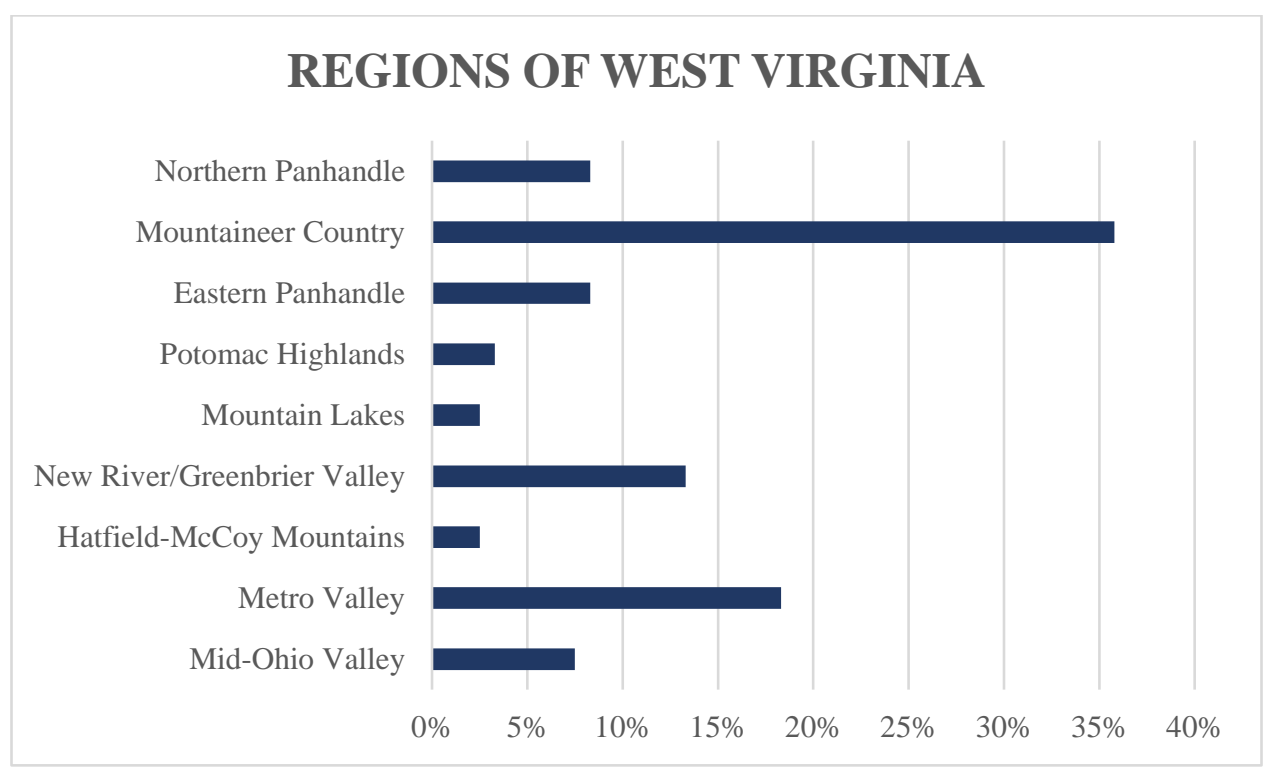


The respondents represented general practices $(75 \%)$, with a general dentist in a corporation $(19.8 \%)$ or a pediatric dental office $(5.2 \%)$. None of the dental hygienists indicate they are working within other dental specialist including periodontist, endodontist, orthodontist, or oral surgery (Figure 2).

Figure 2: Type of Office Dental Hygienist Currently Practices

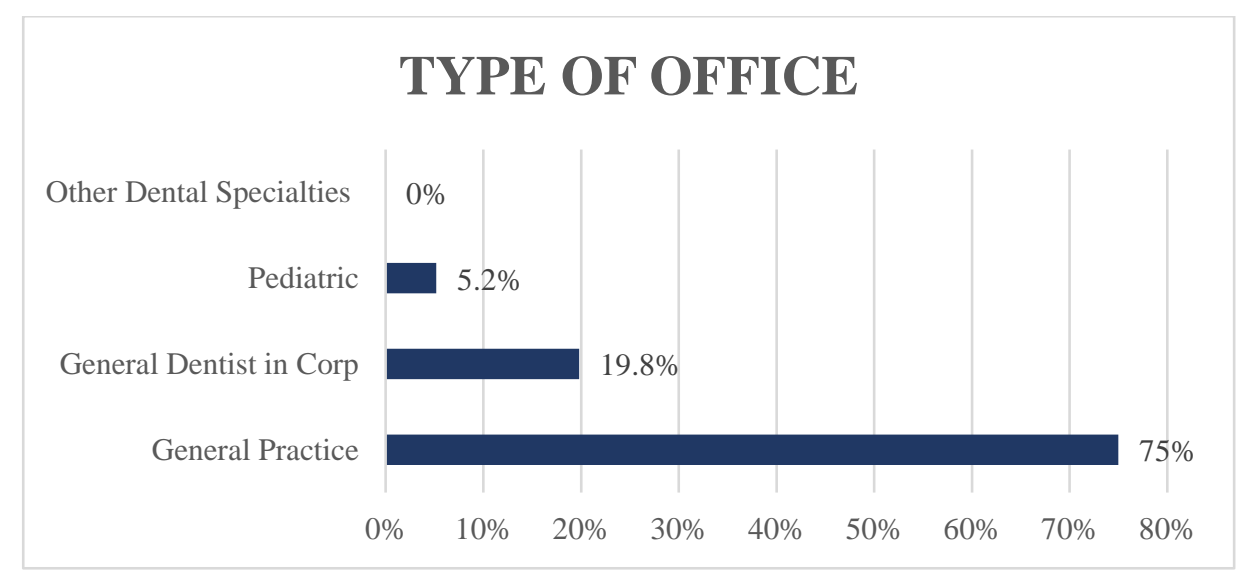

Respondents specified their highest level of education in their field of study as a dental hygienist. Of these, $36.7 \%$ obtain an associate degree, $54.1 \%$ obtain a baccalaureate degree, and 9.2\% obtain their master's degree (Figure 3).

Figure 3: Dental Hygienist's Highest Level of Education

\section{HIGHEST LEVEL OF EDUCATION}

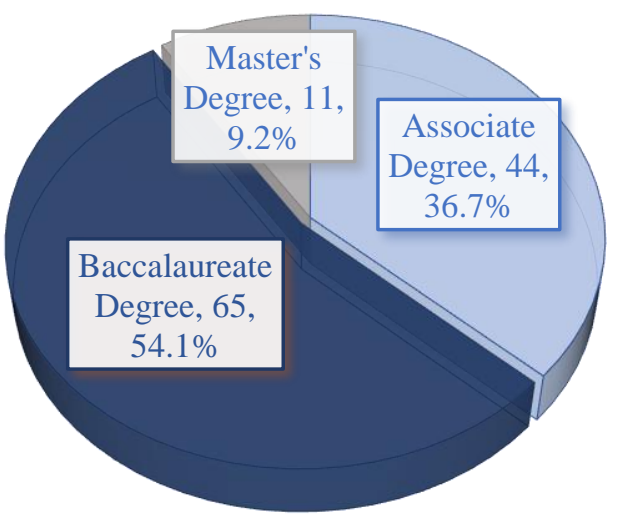


There were $88.5 \%$ of respondents reporting adequate education in providing counseling to pregnant women (36.4\% strongly agree and $52.1 \%$ agree). There were $91.8 \%$ reporting being comfortable educating pregnant women on the importance of good oral health and the potential risk of poor health has on the child's development during pregnancy (46.3\% strongly agree and $45.5 \%$ agree). Figure 4.

Figure 4: Dental Hygienist Feels Adequately Educated and Comfortable Educating

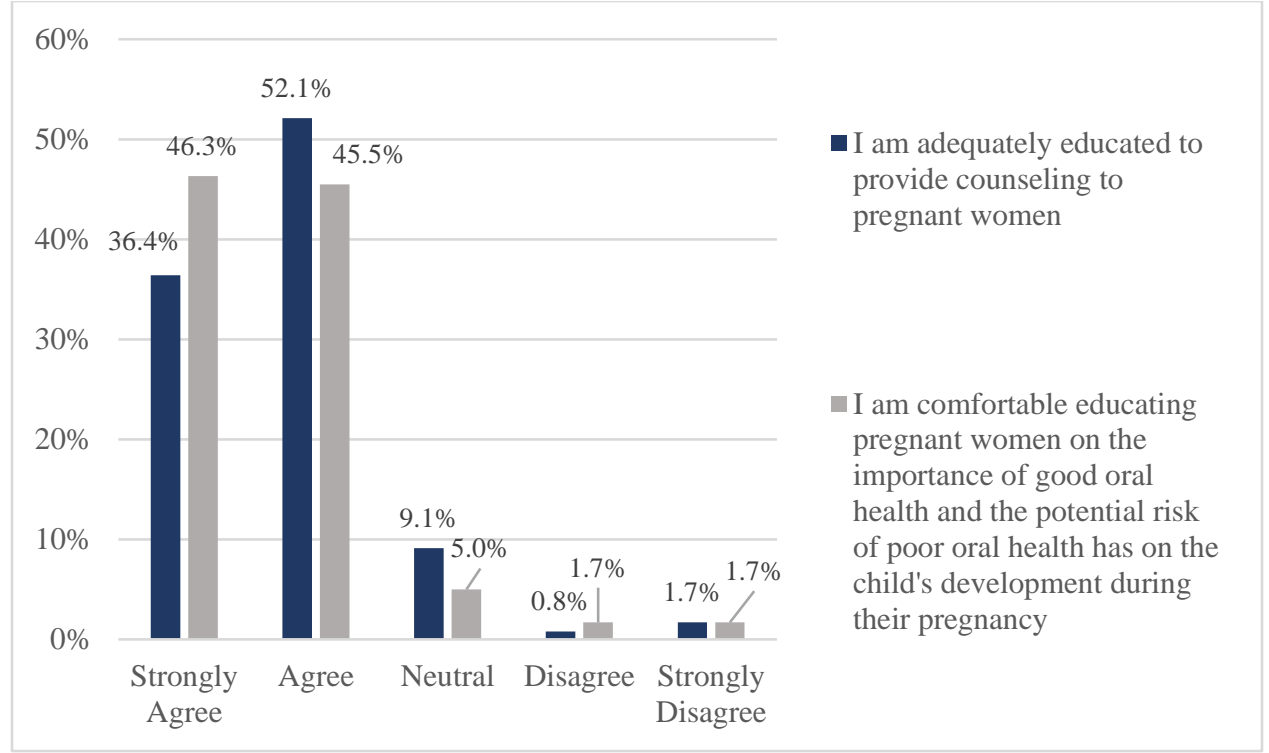


There were $54.6 \%$ of respondents reporting agreement, $21.5 \%$ reporting a neutral response, and $24 \%$ disagreeing that their pregnant patients' knowledge includes the importance of maintaining good oral health throughout their pregnancy. There were $40 \%$ who agreed, $21.7 \%$ reporting a neutral response and $28.3 \%$ disagreed that their pregnant patients are knowledgeable involving the risks associated with poor oral health and the child's development (Figure 5).

Figure 5: Dental Hygienists' Perception of Patient's Knowledge

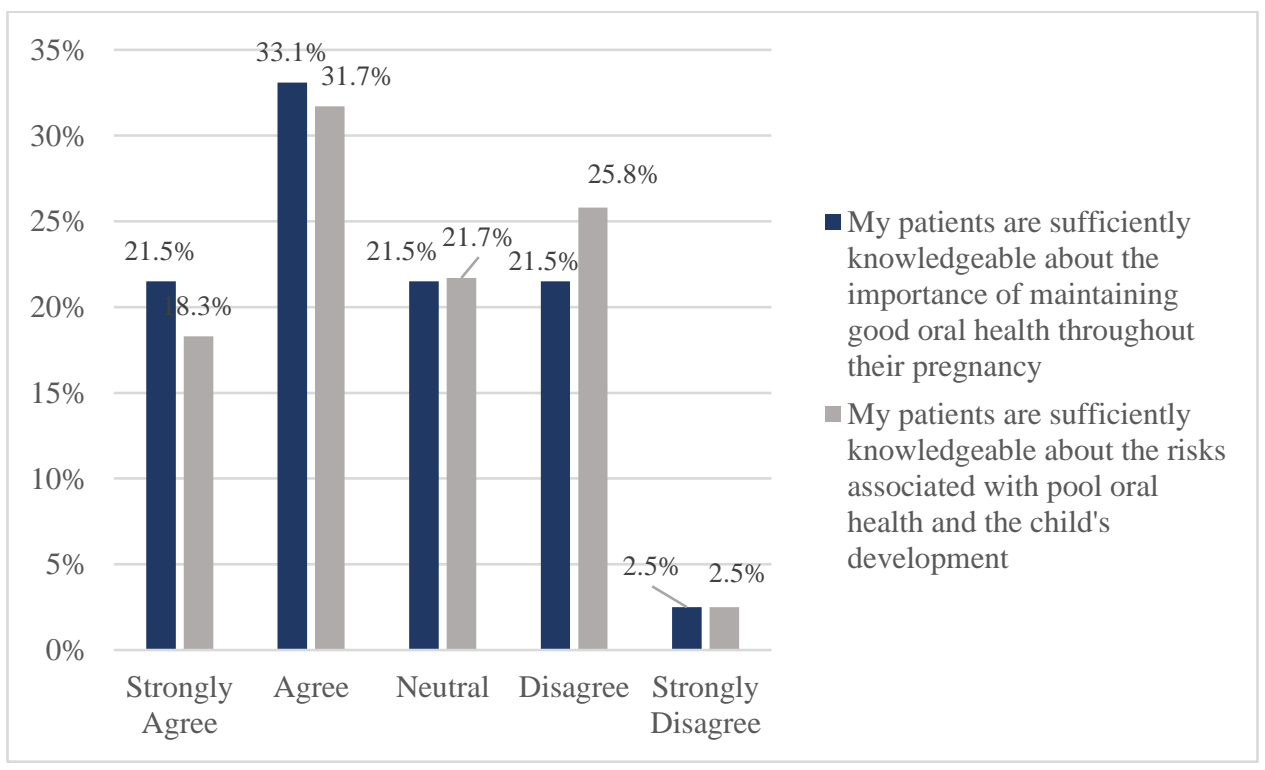




\section{RESPONSES CONCERNING APPOINTMENTS}

The respondents reported they treat from 0 to 10 pregnant patients per a month. There were $33.1 \%$ who reported treating "none or infrequently treated" pregnant women. There were $64.5 \%$ who reported treating 1 to 5 pregnant patients per a month, and $2.5 \%$ who reported treating 6 to 10 pregnant patients per a month (Figure 6). Appointment times to treat pregnant patients were less than 25 minutes $(0.9 \%) ; 25$ to 35 minutes $(7.8 \%) ; 45$ to 55 minutes $(72.2 \%)$; and 65 to 75 minutes (19.1\%). Figure 7 . Respondents were almost equally divided (48.8\% yes and $51.2 \%$ no) on their response to the question, "do you feel additional treatment time is needed for pregnant women" (Figure 8). Ideal appointment times were reported to include an additional 5 minutes (5.5\%), 10 minutes (40\%), 15 minutes (12.7\%), and 20 minutes $(2.7 \%)$. Figure 9.

Figure 6: Number of Patients Seen in a Month

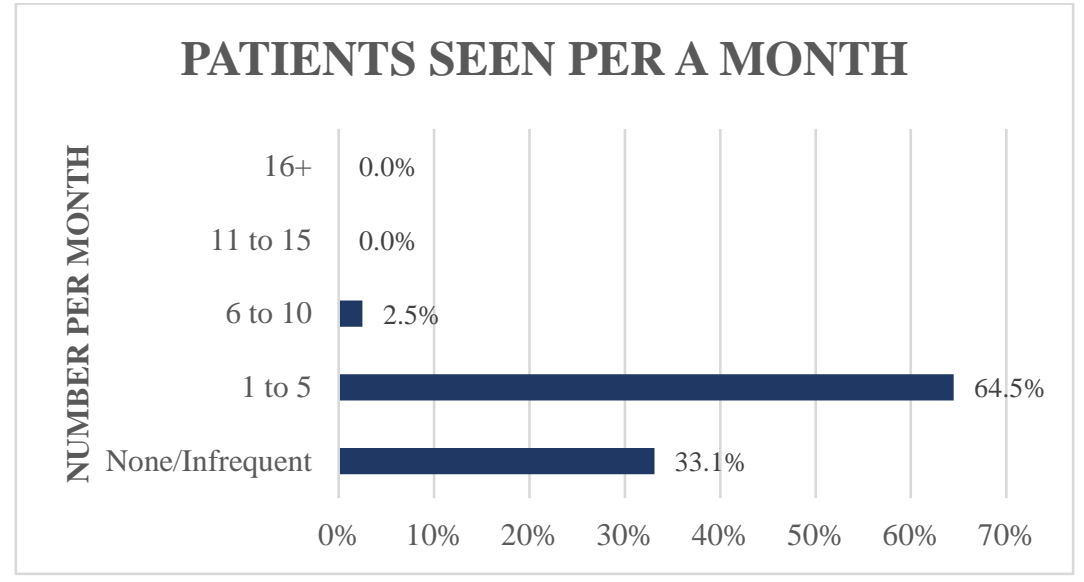

Figure 7: Minutes Allotted for Routine Prophylaxis for Pregnant Women

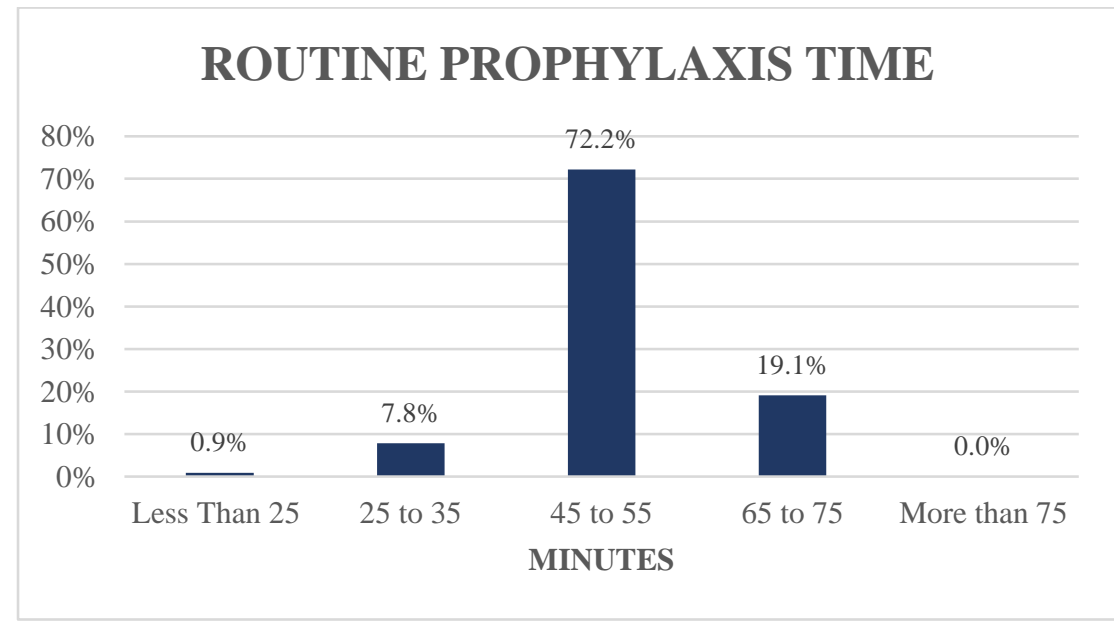


Figure 8: Dental Hygienists Feel Additional Time Needed for Pregnant Women

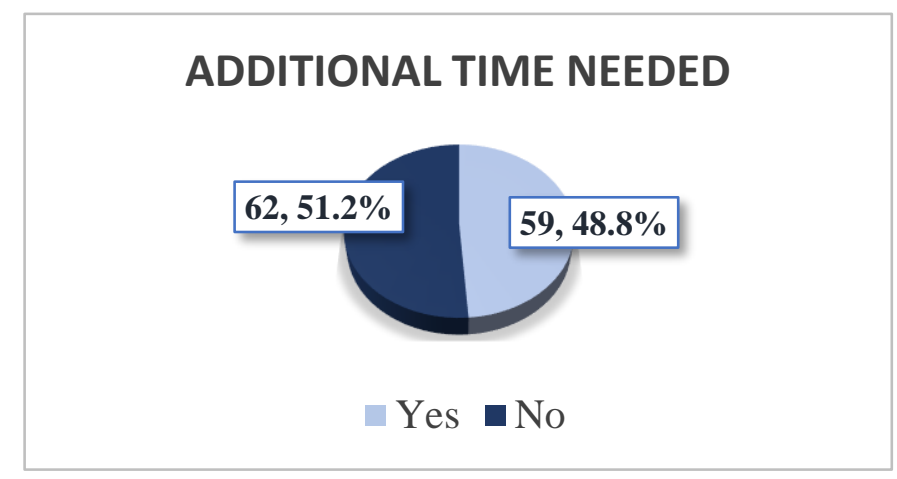

Figure 9: Amount of Additional Treatment Time Dental Hygienists Feels is Needed

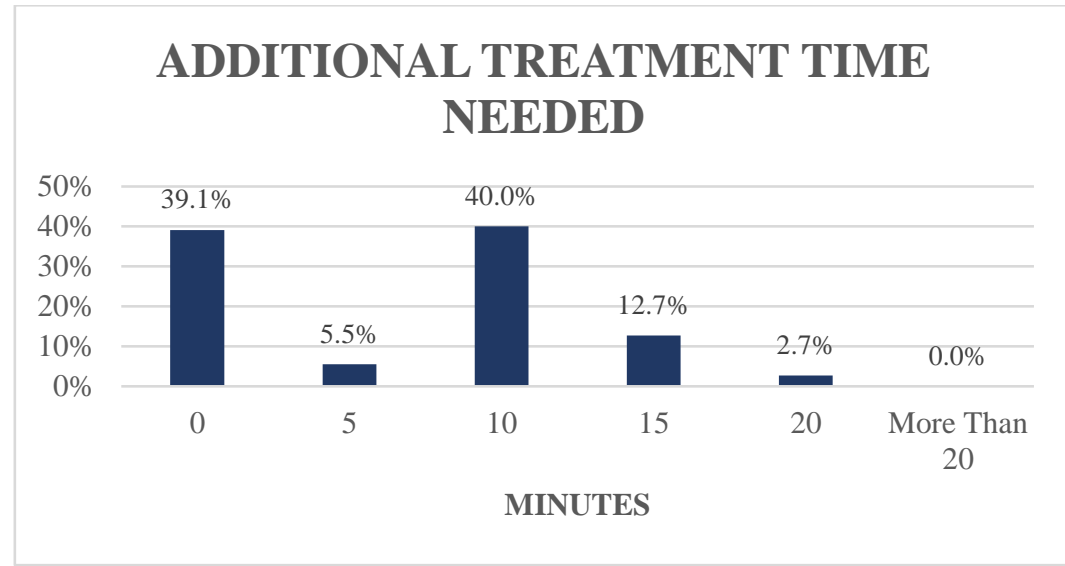

Most respondents who answered their office did not provide additional treatment time for pregnant women also answer "no" their office does not re-appointment the pregnant patient for a separate face-to-face appointment (55.8\%) or telephone (56.7\%) appointment focused on oral hygiene instruction and counseling (Figure 10).

Figure 10: Dental Hygienists' Re-appoint Pregnant Women for Counseling

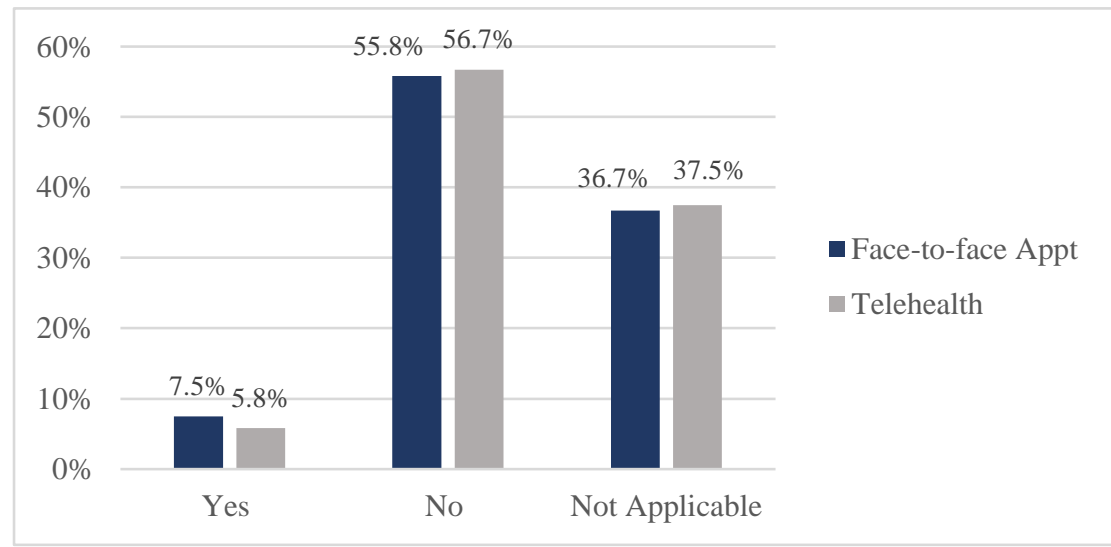


Of the dental hygienists practicing 10 years or less, $38.5 \%$ state they are current knowledge on oral health for pregnant women, and 32\% of dental hygienists practicing 11 year or more feel they are current (Figure 11 and Table 1). This failed to reach a significance difference $(p=0.654)$.

\section{Figure 11: Comparison of Knowledge for the Groups of Dental Hygienists}

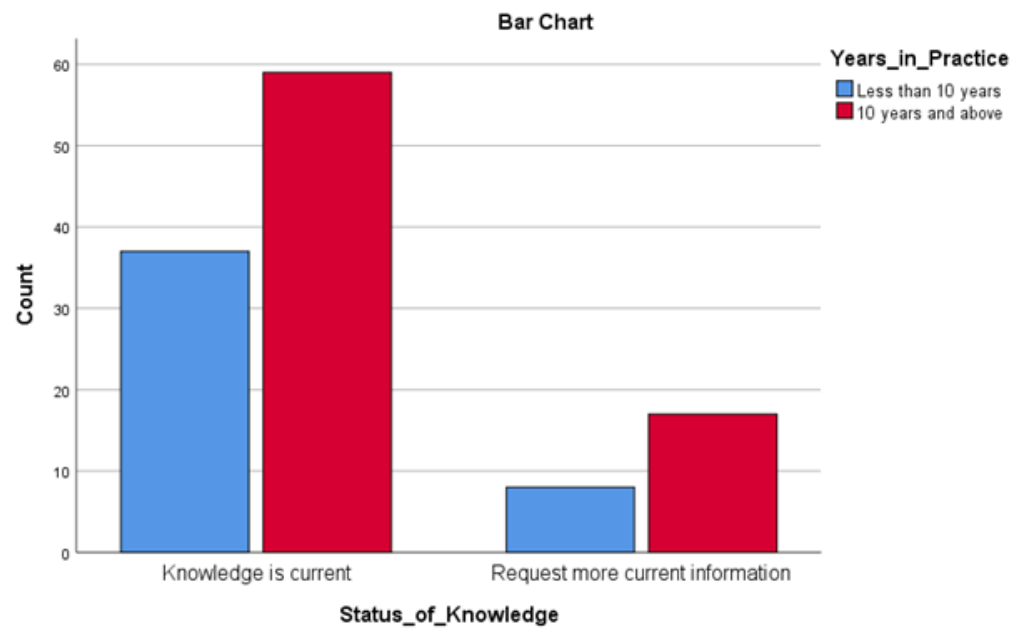

Table 1: Chi-Square Tests: Significance for Groups of Dental Hygienists Knowledge Chi-Square Tests

\begin{tabular}{|c|c|c|c|c|c|c|}
\hline & Value & $\mathrm{df}$ & $\begin{array}{c}\text { Asymptotic Significance } \\
(2-\text { sided })\end{array}$ & $\begin{array}{l}\text { Exact Sig. (2- } \\
\text { sided) }\end{array}$ & $\begin{array}{l}\text { Exact Sig. (1- } \\
\text { sided) }\end{array}$ & $\begin{array}{c}\text { Point } \\
\text { Probability }\end{array}$ \\
\hline Pearson Chi-Square & $.363^{a}$ & 1 & .547 & .645 & .360 & \\
\hline Continuity Correction ${ }^{\circ}$ & .137 & 1 & .711 & & & \\
\hline Likelihood Ratio & .369 & 1 & .543 & .645 & .360 & \\
\hline Fisher's Exact Test & & & & .645 & .360 & \\
\hline $\begin{array}{l}\text { Linear-by-Linear } \\
\text { Association }\end{array}$ & $.360^{\circ}$ & 1 & .548 & .645 & .360 & .157 \\
\hline $\mathrm{N}$ of Valid Cases & 121 & & & & & \\
\hline
\end{tabular}

a. 0 cells $(0.0 \%)$ have expected count less than 5 . The minimum expected count is 9.30 .

b. Computed only for a $2 \times 2$ table

c. The standardized statistic is .600 . 
Dental hygienists practicing ten years or less were less comfortable educating pregnant women on their oral health compared to dental hygienists practicing $>10$ years $(33.6 \%$ versus $66.4 \% ; \mathrm{p}=0.038$ ). (Figure 12 and Table 2).

Figure 12: Comparison of Confidence for the Groups of Dental Hygienists'

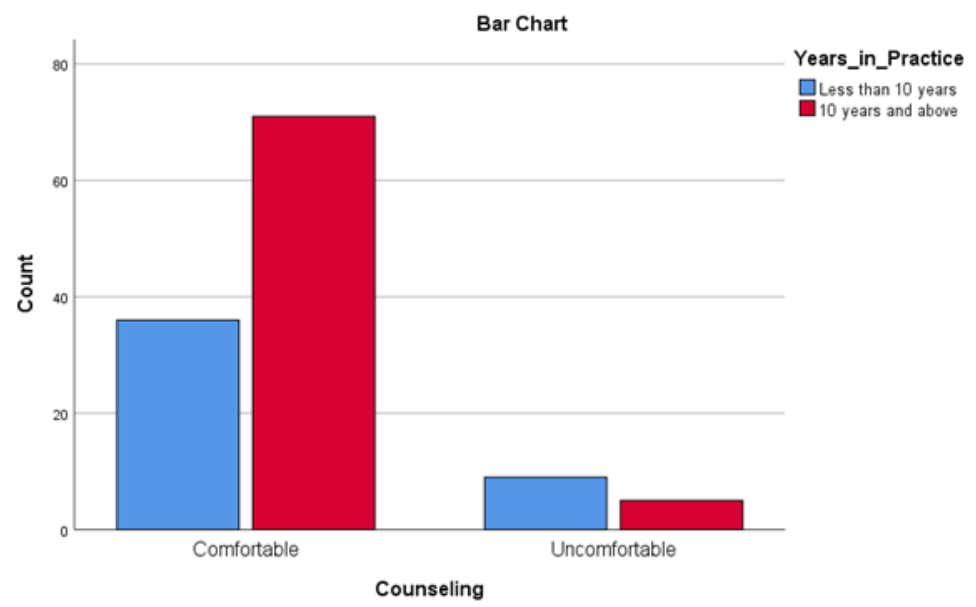

Table 2: Chi-Square Tests: Significance for Groups of Dental Hygienists Confidence

Chi-Square Tests

\begin{tabular}{|c|c|c|c|c|c|c|}
\hline & Value & $\mathrm{df}$ & $\begin{array}{c}\text { Asymptotic Significance } \\
(2 \text {-sided })\end{array}$ & $\begin{array}{l}\text { Exact Sig. (2- } \\
\text { sided) }\end{array}$ & $\begin{array}{l}\text { Exact Sig. (1- } \\
\text { sided) }\end{array}$ & $\begin{array}{c}\text { Point } \\
\text { Probability } \\
\end{array}$ \\
\hline Pearson Chi-Square & $4.976^{a}$ & 1 & .026 & .038 & .028 & \\
\hline Continuity Correction ${ }^{b}$ & 3.751 & 1 & .053 & & & \\
\hline Likelihood Ratio & 4.790 & 1 & .029 & .038 & .028 & \\
\hline Fisher's Exact Test & & & & .038 & .028 & \\
\hline $\begin{array}{l}\text { Linear-by-Linear } \\
\text { Association }\end{array}$ & $4.935^{\circ}$ & 1 & .026 & .038 & .028 & .022 \\
\hline $\mathrm{N}$ of Valid Cases & 121 & & & & & \\
\hline
\end{tabular}

a. 0 cells $(0.0 \%)$ have expected count less than 5 . The minimum expected count is 5.21 .

b. Computed only for a $2 \times 2$ table

c. The standardized statistic is -2.221 . 
Ninety-two dental hygienists self-reported confidence in their current knowledge about pregnancy gingivitis, and correctly agreed that "Pregnant women are 60-75\% more likely to experience gingivitis due to an increase of plaque biofilm and hormonal changes during their second and third trimester." Four dental hygienists self-reporting confidence in their current knowledge indicated the statement was false.

Nineteen dental hygienists self-reported lack of information and correctly agreed with the statement. Six dental hygienists self-reporting lack of information reported it was false.

Dental hygienists reporting lack of information were more likely to respond that the statement was false than dental hygienists reporting current knowledge $(p=0.005)$ (Figure 13 and Table 3).

\section{Figure 13: Comparison of Self-Perceived Confidence and Pregnancy Gingivitis Knowledge}

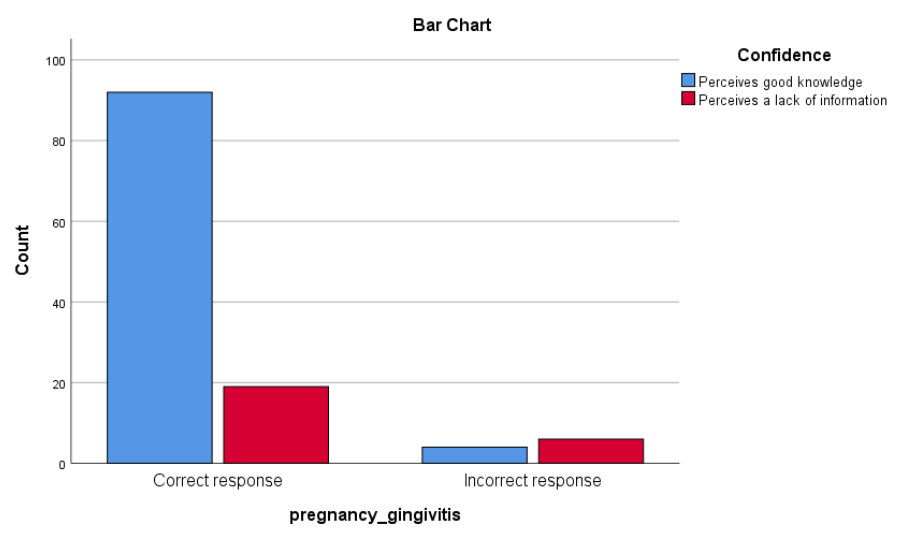

Table 3: Chi-Square Test: Confidence in knowledge and Pregnancy Gingivitis

\begin{tabular}{|c|c|c|c|c|c|c|}
\hline \multicolumn{7}{|c|}{ Chi-Square Tests } \\
\hline & Value & & $\begin{array}{l}\text { Asymptotic Significance (2- } \\
\text { f sided) }\end{array}$ & $\begin{array}{l}\text { Exact Sig. (2- } \\
\text { sided) }\end{array}$ & $\begin{array}{l}\text { Exact Sig. (1- } \\
\text { sided) }\end{array}$ & $\begin{array}{l}\text { Point } \\
\text { Probability }\end{array}$ \\
\hline Pearson Chi-Square & $10.291^{\mathrm{a}}$ & 1 & .001 & .005 & .005 & \\
\hline Continuity Correction ${ }^{b}$ & 7.841 & 1 & .005 & & & \\
\hline Likelihood Ratio & 8.205 & 1 & .004 & .005 & .005 & \\
\hline Fisher's Exact Test & & & & .005 & .005 & \\
\hline $\begin{array}{l}\text { Linear-by-Linear } \\
\text { Association }\end{array}$ & $10.206^{c}$ & & .001 & .005 & .005 & .005 \\
\hline $\mathrm{N}$ of Valid Cases & 121 & & & & & \\
\hline
\end{tabular}


Eighty-seven dental hygienists self-reported confidence in current knowledge about preterm birth and low birthweight babies, and correctly agreed that "Pregnant women with poor oral health during pregnancy are more likely to experience adverse pregnancy outcomes such as preterm birth and low birthweight babies." Nine dental hygienists self-reporting confidence in current knowledge indicated the statement was false.

Nine dental hygienists self-reported lack of information and correctly agreed with the statement. Six dental hygienists self-reporting lack of knowledge responded that the statement was false.

Dental hygienists reporting a lack of information were more likely to respond that the statement was false than dental hygienists reporting current knowledge $(\mathrm{p}=0.041)$ (Figure 14 and Table 4).

\section{Figure 14: Comparison of Self-Perceived Confidence of Preterm Birth and Low Birthweight (PTB_LBW)}

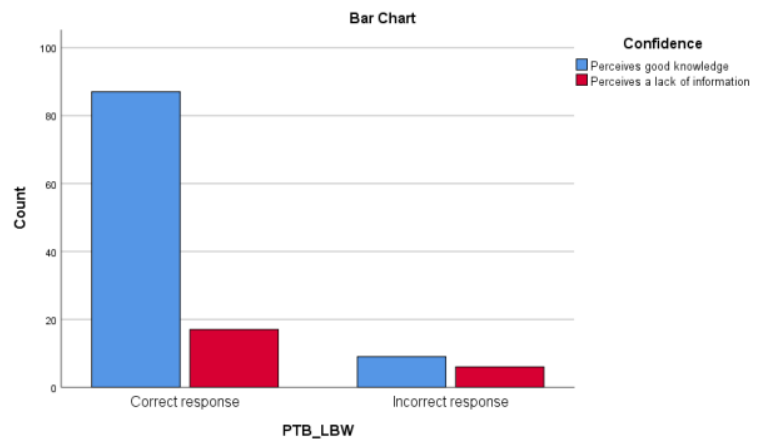

Table 4: Chi-Square Test: Confidence in Knowledge and PTB LBW

Chi-Square Tests

\begin{tabular}{|c|c|c|c|c|c|}
\hline & Value & $\begin{array}{l}\text { Asymptotic Significance (2- } \\
\text { df sided) }\end{array}$ & $\begin{array}{l}\text { Exact Sig. (2- } \\
\text { sided) }\end{array}$ & $\begin{array}{l}\text { Exact Sig. (1- } \\
\text { sided) }\end{array}$ & $\begin{array}{l}\text { Point } \\
\text { Probability }\end{array}$ \\
\hline Pearson Chi-Square & $4.704^{a}$ & 1.030 & .041 & .041 & \\
\hline Continuity Correction ${ }^{b}$ & 3.309 & 1.069 & & & \\
\hline Likelihood Ratio & 4.017 & 1.045 & .073 & .041 & \\
\hline Fisher's Exact Test & & & .073 & .041 & \\
\hline $\begin{array}{l}\text { Linear-by-Linear } \\
\text { Association }\end{array}$ & $4.665^{c}$ & c 1.031 & .041 & .041 & .032 \\
\hline $\mathrm{N}$ of Valid Cases & 119 & & & & \\
\hline
\end{tabular}




\section{DISCUSSION}

Previous researchers have reported hormonal changes may impact pregnant women by increasing their likelihood of experiencing changes in their oral health. These changes may lead to a form of periodontal disease known as pregnancy gingivitis, as well as other conditions. Some evidence has suggested pregnant women's oral health can impact the health of their developing child. To establish a better understanding of the oral health care education provided to pregnant patients by practicing dental hygienist in West Virginia, a survey assessing dental hygienists current knowledge and confidence was distributed. The goals of the survey were to determine if additional continuing education (CE) courses regarding women's oral health during pregnancy need to be completed by dental hygienists in the state.

In terms of dental hygienists' knowledge, from this study, I observed that most practicing dental hygienist in West Virginia are aware of the impact hormonal changes have during pregnancy regarding the women's oral health and the risks associated with periodontal disease. Practicing dental hygienists in West Virginia feel they are knowledgeable about pregnant women's oral health. There were no significant differences between dental hygienists in practice 10 years or less or $>10$ years in their responses to the survey questions about knowledge. These results are consistent with previous studies evaluating the knowledge of Michigan state dental hygienists where the dental hygienists reported positive knowledge, attitude, and behavior regarding oral health care during pregnancy (Schramm, 2019).

For the second aim of the study, confidence, dental hygienists who have practiced ten year or less did not feel as confident as dental hygienists who practiced $>10$ year in educating their pregnant patients. This difference was statistically significant and indicates a possible need for continuing education (CE) courses for newly practicing dental hygienists or additional simulation laboratory sessions prior to graduating to increase their confidence. The researchers in a North Carolina study reported hygienists were confident about discussing potential risks associated with pregnancy. Most (less than 70\%) reported being uncomfortable treating patients at risk for adverse pregnancy outcomes (Bell, 2011). Although, the North Carolina researchers did not report years of practicing, their findings are consistent with the results of this study where most of the West Virginia dental hygienists reported being confident about educating their pregnant patients about risks during pregnancy. 
The results of this study reveal an area of concern: why are dental hygienists with fewer years of practice less confidence providing education to pregnant women? Nearly half, 48.8\%, of practicing West Virginia dental hygienists responded they felt no additional treatment time is needed for pregnant women and $88.5 \%$ felt they are adequately educated to provide oral health education to pregnant patients. And yet, there is less confidence in dental hygienists with $\leq 10$ years of practice.

One possible explanation, as offered by Bell et al (2011) is that dental hygienists may not understand their role in interprofessional care. It is important for dental hygienists to feel confident to participate fully in their role in a dental office, working collaboratively with other professionals.

Another explanation is that dental hygienists need more practice to feel comfortable in their role as an educator. Researchers studied Michigan dental hygiene students practicing motivational interviews (MI) techniques. They demonstrated improved comfort in educating patients after the sessions (Mills, 2017). Perhaps similar practices should be implemented throughout dental hygiene education programs.

\section{Study strengths and limitations}

This study has several strengths and limitations. A study strength was that all registered and licensed dental hygienists in the state were provided access to the survey and the response rate was acceptable at $12.5 \%$. Additionally, the survey was presented with two reminders, so the maximum reach occurred.

A limitation is that aa an anonymous survey it was not possible to check for duplicates. It is possible that one participant may have responded multiple times to the survey. Additional questions would have strengthened the survey. I did not ask about dental hygienists' willingness to participant in CE courses related to pregnant women's oral health and associated risk. I also did not ask about the dental hygienists' comfortability in preforming periodontal therapy on pregnant patients at risk for adverse pregnancy outcomes.

\section{Future implications}

This study brings an important issue to the forefront. If there is less confidence in discussing one issue, could there also be concerns about topics such as receiving HPV vaccinations or discussing the consequences of sensitive issues such as sexually transmitted diseases and oral health? This is an area that should receive additional research. 


\section{CONCLUSION}

In summary, the dental hygienists felt confident in their current knowledge; however, practitioners who had 10 or fewer years of experience had less confidence in their ability to provide needed education concerning oral health and pregnancy. As a continuing education needs assessment project, the researcher of this study indicates a need for dental hygienists who have been practicing for less than 10 years to participant in confidence building activities so they can better educate pregnant patients.

\section{RECOMMENDATIONS}

To better compare the dental hygienists' knowledge and confidence, additional research would need to include more demographic information such as gender and age. It was assumed that most of the dental hygienists were female practitioners. This would be important to include since dental hygienists who have personally experienced childbirth may be more confident about providing oral health education to their pregnant patients.

Additionally, it would strengthen the research to compare all dental hygienists' perceived knowledge and self-reported confidence to the demographic questions: 1) highest level of education and 2) regions of West Virginia currently practicing. These comparisons would help indicate a need for continuing education for dental hygienists based on their educational level and the region of West Virginia they currently practice.

Since there is evidence indicating dental hygienists with fewer than 10 years lack confidence for providing oral health to pregnant patients, additional research is needed to investigate if there is a lack of confidence in presenting oral health information to patients with other sensitive topics. An example of another sensitive topic would include such as oral cancer related to the Human papillomavirus infection virus (HPV). 


\section{REFERENCES}

1. American Academy of Periodontology. 2019. Expectant Mother's Periodontal Health Vital to Health of Her Baby. https://www.perio.org/consumer/AAP_EFP_Pregnancy Accessed 19 November 2020.

2. American Academy of Periodontology. 2019. Periodontal Disease Fact Sheet.

https://www.perio.org/newsroom/periodontal-disease-fact-sheet Accessed 19 November 2020.

3. American Academy of Periodontology. 2019. Types of Gum Disease.

https://www.perio.org/consumer/types-gum-disease.html Accessed 19 November 2020.

4. American Pregnancy Association. 2017. Premature Birth Complications.

https://americanpregnancy.org/labor-and-birth/premature-birth-complications/Accessed 19 November 2020.

5. American Pregnancy Association. 2019. Pregnancy and Dental Work.

https://americanpregnancy.org/healthy-pregnancy/is-it-safe/dental-work-and-pregnancy-1185/ Accessed 19 November 2020.

6. Azofeifa, A., Yeung, L.F., Alverson, C.J., Beltrán-Aguilar, E., 2016. Dental caries and periodontal disease among U.S. pregnant women and nonpregnant women of reproductive age, National Health and Nutrition Examination Survey, 1999-2004. Journal of Public Health Dentistry.. doi:10.1111/jphd.12159

7. Bell, K.P., Phillips, C., Paquette, D.W., Offenbacher, S., Wilder, R.S., 2012. Dental Hygienists' Knowledge and Opinions of Oral-Systemic Connections: Implications for Education. Journal of Dental Education.. doi:10.1002/j.0022-0337.2012.76.6.tb05302.x

8. Bobetsis, Y. A., Graziani, F., Gürsoy, M., \& Madianos, P. N. 2020. Periodontal disease and adverse pregnancy outcomes. Periodontology 2000, 83(1), 154-174. doi:10.1111/prd.12294

9. Center for Devices and Radiological Health. 2017. Pregnancy and You. U.S. Food \& Drug Administration. https://www.fda.gov/radiation-emitting-products/medical-x-ray-imaging/xrays-pregnancy-and-you Accessed 19 November 2020. 
10. Center for Disease Control and Prevention. 2019. Oral Health: Pregnancy and Oral Health. https://www.cdc.gov/oralhealth/publications/features/pregnancy-and-oral-health.html Accessed 19 November 2020.

11. Center for Disease Control and Prevention. 2020. Reproductive Health: Premature Birth. https://www.cdc.gov/reproductivehealth/features/premature-birth/index.html Accessed 19 November 2020.

12. Centers for Disease Control and Prevention. 2013. Oral Health: Periodontal Disease. https://www.cdc.gov/oralhealth/conditions/periodontal-disease.html Accessed 19 November 2020.

13. Department of Scientific Information, Evidence Synthesis \& Translation Research. 2019. Oral Health Topics: Pregnancy. American Dental Association. https://www.ada.org/en/member-center/oralhealth-topics/pregnancy Accessed 19 November 2020.

14. Gehrig, J. S., \& Willmann, D. E. 2008. Chapter 14 - Plaque-Associated Gingival Disease with Modifying Factors. In Foundations of periodontics for the dental hygienist. Philadephia: Lippincott Williams \& Wilkins.

15. Gehrig, J. S., \& Willmann, D. E. 2008. Chapter 4 - Classifying Periodontal Disease Versus Periodontitis. In Foundations of periodontics for the dental hygienist. Philadephia: Lippincott Williams \& Wilkins.

16. Giglio JA, Lanni SM, Laskin DM, Giglio NW. Oral health care for the pregnant patient. J Can Dent Assoc. 2009 Feb;75(1):43-8. PMID: 19239743.

17. Kloetzel, M.K., Huebner, C.E., Milgrom, P., Littell, C.T., Eggertsson, H., 2012. Oral health in pregnancy: educational needs of dental professionals and office staff. Journal of Public Health Dentistry.. doi:10.1111/j.1752-7325.2012.00333.x

18. Latorre Uriza, C., Velosa-Porras, J., Roa, N.S., Quiñones Lara, S.M., Silva, J., Ruiz, A.J., Escobar Arregoces, F.M., 2018. Periodontal Disease, Inflammatory Cytokines, and PGE2 in Pregnant Patients at Risk of Preterm Delivery: A Pilot Study. Infectious Diseases in Obstetrics and Gynecology.. doi:10.1155/2018/7027683

19. Lee, R.S.-Y., Milgrom, P., Huebner, C.E., Conrad, D.A., 2010. Dentists' Perceptions of Barriers to 
Providing Dental Care to Pregnant Women. Women s Health Issues..

doi:10.1016/j.whi.2010.05.007

20. Mann, J., Bernstein, Y., Findler, M., 2019. Periodontal disease and its prevention, by traditional and new avenues (Review). Experimental and Therapeutic Medicine.. doi:10.3892/etm.2019.8381

21. Murakami, S., Mealey, B.L., Mariotti, A., Chapple, I.L.C., 2018. Dental plaque-induced gingival conditions. Journal of Clinical Periodontology.. doi:10.1111/jcpe.12937

22. PA Harris, R Taylor, R Thielke, J Payne, N Gonzalez, JG. Conde, Research electronic data capture (REDCap). 2009. A metadata-driven methodology and workflow process for providing translational research informatics support, J Biomed Inform. 42(2):377-81.

23. Robin Dimatteo, M., Giordani, P.J., Lepper, H.S., Croghan, T.W., 2002. Patient Adherence and Medical Treatment Outcomes. Medical Care.. doi:10.1097/00005650-200209000-00009

24. Romero BC, Chiquito CS, Elejalde LE, Bernardoni CB. Relationship between periodontal disease in pregnant women and the nutritional condition of their newborns. J Periodontol. 2002 Oct;73(10):1177-83. doi: 10.1902/jop.2002.73.10.1177. PMID: 12416776.

25. Schramm SA, Jacks ME, Prihoda TJ, McComas MJ, Hernandez EE. Oral Care for Pregnant Patients: A Survey of Dental Hygienists' Knowledge, Attitudes and Practice. J Dent Hyg. 2016 Apr;90(2):121-7. PMID: 27105790.

26. Shanafelt, T.D., Boone, S., Tan, L., Dyrbye, L.N., Sotile, W., Satele, D., West, C.P., Sloan, J., Oreskovich, M.R., 2012. Burnout and Satisfaction With Work-Life Balance Among US Physicians Relative to the General US Population. Archives of Internal Medicine.. doi:10.1001/archinternmed.2012.3199

27. Shira Davenport, E., 2010. Preterm low birthweight and the role of oral bacteria. Journal of Oral Microbiology.. doi:10.3402/jom.v2i0.5779

28. Silk, Hugh, Douglass, Alan B., Douglass Joanna M., Silk, Laura. Oral Health During Pregnancy. 2008. American Family Physician. 15;77(8):1138-1144.

29. The American College of Obstetricians and Gynecologist. 2020. How Your Fetus Grows During 
Pregnancy. https://www.acog.org/womens-health/faqs/how-your-fetus-grows-duringpregnancy Accessed 19 November 2020.

30. Vogel, Joshua P., Chawanpaiboon, Saifon, Moller, Ann-Beth, Watananirun, Kanokwaroon, Boney, Mercedes, \& Lumbiganon, Pisake. 2018. The Global Epidemiology of Preterm Birth. Best Practice \& Research Clinical Obstetrics \& Gynecology. 52(p.3-12). https://doi.org/10.1016/j.bpobgyn.2018.04.003.

31. Wei Guang Bi, Elham Emami, Zhong-Cheng Luo, Christina Santamaria \& Shu Qin Wei. 2019. Effect of periodontal treatment in pregnancy on perinatal outcomes: a systematic review and metaanalysis, The Journal of Maternal-Fetal \& Neonatal Medicine, DOI: 10.1080/14767058.2019.1678142

32. World Health Organization. 2018. Preterm Birth. https://www.who.int/news-room/factsheets/detail/preterm-birth Accessed 19 November 2020. 
APPENDIX A

Cover Letter 


\section{WWestVirininiaUniversity.}

Dear Participant,

This letter is a request for you to take part in a research project WV Dental Hygienist's Knowledge and Educational Approach for Pregnant Women. This project is being used to understand the approaches you, as the dental hygienist, use for counselling pregnancy women on their oral health. This project is being conducted by Isabella McDaniel, under the supervision of Dr. Alcinda Shockey, a professor in the School of Dentistry Department of Dental Hygiene, for completion of her Master of Science in Dental Hygiene. Your participation in this project is greatly appreciated and will take approximately 10 minutes to fill out the attached questionnaire.

Your involvement in this project will be kept as confidential as legally possible. All data will be reported in the aggregate. You must be a registered dental hygienist in the state of West Virginia to participate. We will not ask any information that would lead back to your identity as a participant. Your participation is completely voluntary. You may skip any question that you do not wish to answer, and you may discontinue at any time. Your treatment will not be affected if you decide either not to participate or to withdraw. West Virginia University's Institutional Review Board acknowledgement of this project is on file.

We hope that you will participate in this research project, as it could be beneficial in understanding approaches used for pregnant women. Thank you very much for your time. Should you have any questions about this letter or the research project, please feel free to contact Isabella McDaniel at (304) 222-5652 or by e-mail at ihmcdaniel@mix.wut.edu.

Thank you for your time and help with this project.

Sincerely,

Isabella McDaniel

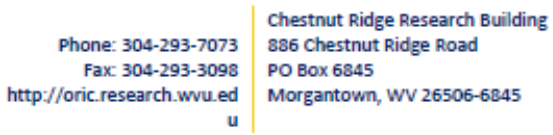




\section{APPENDIX B}

WV Dental Hygienists' Knowledge and Educational Approaches for Pregnant Women 
WV Dental Hygienists' Knowledge and Educational

Approaches for Pregnant Women

Many pregnant women will experience gingivitis during their pregnancy due to an increase in plaque biofilm and hormonal changes. Previous research has shown a tentative association of periodontitis and adverse pregnancy outcomes such as pre-term birth and low birth weight babies. This study is designed to assess the need for specific continuing education related to caring for pregnant women by surveying West Virginia dental hygienists' knowledge and approaches regarding the care of pregnant patients.

This project is being conducted by Isabella McDaniel RDH, BSDH, under the supervision of Dr. Alcinda Shockey, a professor at WVU School of Dentistry Department of Dental Hygiene, for completion of her Master of Science in Dental Hygiene. Your participation in this project should take approximately 5 minutes and is greatly appreciated!

Thank you!

Please indicate how strongly you agree or disagree with the following statements: Strongly agree Agree Neutral Disagree Strongly
disagree

1) I am adequately educated to provide counseling to pregnant $\mathrm{O}$ O

$\bigcirc$

$\mathrm{O}$

O

women

2) Pregnant women are $60 \%$ to $75 \%$ more likely to experience gingivitis due to an increase of plaque, biofilm, and hormonal changes during their second and third trimester

3) I am comfortable educating pregnant women on the importance of good oral health and the potential risk of poor oral health has on the child's development during their pregnancy.

4) Pregnant women with poor ora health during pregnancy are more likely to experience adverse pregnancy outcomes such as pre-term birth and low birth weight baby.

5) A comprehensive exam including a periodontal chart should be completed on pregnant women to evaluate their periodonta health.

6) My knowledge of oral health during pregnancy is current.

O

O

O

O

7) 
My patients are sufficiently knowledgeable about the

importance of maintaining good

oral health throughout their

pregnancy.

8) My patients are sufficiently knowledgeable about the risks associated with poor oral health and the child's development.

O

O

O

O

O

For the following questions please answer based on the protocols your current office uses for pregnant women seen by you, the dental hygienist:

9) On average, how many pregnant None/infrequent

$1-5$
0

0

1-5

$6-10$

$\mathrm{C}^{6-10}$

$11-15$

$0^{11-15}$

$16+$ month?

10) Routinely, pregnant women are scheduled minutes for a prophylaxis.

Less than 25

L $25-35$

$45 \cdot 55$

$65-75$

More than 75

11) As the dental hygienist, do you have control over your schedule allowing you to add an extra 10

minutes for unexpected treatment needs when caring $\quad$ Not Applicable for pregnant women?

12) As the dental hygienist, do you feel additional treatment time is needed for pregnant women?

$$
\begin{aligned}
& \text { Yes } \\
& \text { No }
\end{aligned}
$$

13) If you feel additional treatment time is needed for pregnant women, please indicate how much time you feel is necessary.

0 minutes

5 minutes

10 minutes

15 minutes

20 minutes

More than 20 minutes

14)

If your office does not include additional treatment time for pregnant women, do you re-appoint the patient for a separate, face-to-face appointment focused on oral hygiene instruction and counseling if the patient agrees?

$\square$ Yes

$\square$ Not Applicable

15) If your office does not include additional treatment time for pregnant women, do you re-appoint the patient for a separate appoint focused on oral hygiene instruction and counseling over the telephone if the patient agrees?

Y Yes

ONo

Not Applicable 
16) Please indicate if your office utilizes the American Dental Association code D4346 "Scaling in the Presence of Moderate to Severe Gingival Inflammation" regarding pregnant women when necessary.

17)

$\begin{array}{ll}\text { Please indicate if your office utilizes the American } & \text { Yes } \\ \text { Dental Association code D1330 "Oral Hygiene } & \text { No }\end{array}$
Instruction" regarding counseling pregnant women.

Demographics

Yes

$\bigcirc$ Not Applicable

No

\begin{tabular}{|c|c|}
\hline $\begin{array}{lc}\text { Please indicate your highest } & \text { Associate's Degree } \\
\text { level of education in your field. } & \end{array}$ & $\begin{array}{c}\text { Baccalaureate Degre } \\
0\end{array}$ \\
\hline How long have you been a registered dental hygienist? & $\begin{array}{l}\bigcirc \text { Less than a year } \\
\text { 1-4 years } \\
5-10 \text { years } \\
11-15 \text { years } \\
16-20 \text { years } \\
\text {. } 21+\text { years }\end{array}$ \\
\hline
\end{tabular}

20) Please select the type of practice you currently work for.

General Dentist in a private practic

General Dentist in a corporation

Pediatric

Periodontist

Endodontist

Orthodontist

Oral Surgery

21) Please select which region of West Virginia you practice in:

Northern Panhandle (Hancock, Brooks, Ohio, Marshall, Wetzel, and Tyler)

Mountaineer Country (Monongalia, Marion, Preston, Taylor, Harrison, Barbour, and Doddridge

Eastern Panhandle (Morgan, Berkley, Jefferson)

Potomac Highlands (Mineral, Hampshire, Hardy, Grant, Pendleton, Tucker, Randolph, and Pocahontas)

Mountain Lakes (Gilmer, Lewis, Upshur, Webster, Nicholas, Clay, and Braxton)

New River/Greenbrier Valley (Fayette, Greenbrier, Monroe, Summers, Wyoming, McDowell, and Mercer

Hatfield-McCoy Mountains (Lincoln, Boone, Logan, Mingo, and Wayne)

Metro Valley (Mason, Cabell, Putnam, and Kanawha)

Mid-Ohio Valley (Pleasant, Ritchie, Calhoun. Roane, Jackson, Wirt, and Wood) 
APPENDIX C

IRB Approval Letter 


\section{WhestVirginiaUniversity.}

OFFICE OF HUMAN RESEARCH PROTECTIONS

826 Chestrut Ridge Rosd Morgantown, WN 26506

\section{Approval of Protocol Renewal}

$09 / 21 / 2020$

To: Alcinda Trickett Shockey

From: WVU Human Research Protection Program

Protocol Type: NHSR / Flex

Approval Date: 09/21/2020

Submission Type: Renewal

Expiration Date: 09/20/2025

Funding: N/A

WVU Protocol \#: 1912821062R001

Protocol Title: Infant Oral Healthcare for Mothers

The West Virginia University Institutional Review Board has reviewed and granted your request for re-approval of NHSR / Flex protocol 1912821062R001, in accordance with the Federal regulations 45 CFR 46, 21 CFR 50, and 21 CFR 56 (when applicable). Additional details concerning the review are below:

- FLEX: The review of the above referenced protocol was conducted in accordance with the ethical principles of the Belmont Report. The protocol meets the criteria for approval Flex Model Review because the project does not have federal funding, is considered to be minimal risk, and falls within the guidelines of the WVU Flex Model as of this approval date.

The following documents were reviewed and approved for use as part of this submission. Only the documents listed below may be used in the research. Please access and print the files in the Notes \& Attachments section of your approved protocol.

- Cover Letter.docx

- Capstone Lit Review.docx

- Thesis Survey.docx

- HIPAA Waiver Form.docx

- Cover Letter updated.pdf 
- Survey Final Updated.pdf

WVU IRB approval of protocol 1912821062R001 will expire on 09/20/2025.

Once you begin your project, the following apply:

1. Unanticipated, serious adverse events and/or side effect(s) encountered at WVU or an affiliate site that are related to the research must be reported to the WVU IRB within five (5) days using the Notify IRB action in WVU+kc.

2. Any Unanticipated Problem or UPIRTSO or other research related event resulting in new or increased risk of harm to study subjects, occurring at WVU or an affiliate site, must be reported to the WVU IRB within five (5) days using the Notify IRB action in WVU+kc.

3. All research personnel performing tasks related to the research must complete and remain current for the required training as applicable to the protocol referenced above.

4. Only Flex Consent Forms with the WVU+ke watermark may be used to consent participants.

5. The IRB must be notified if there is an increase in risk to participants or if federal funding is awarded to conduct research under this protocol. These modifications must be submitted as an amendment in WVU+kc.

The WVU Human Research Protection Program will be glad to provide assistance to you throughout the research process. Please feel free to contact us by phone at 304.293 .7073 or by email at IRB@mail.wvu.edu.

Sincerely,

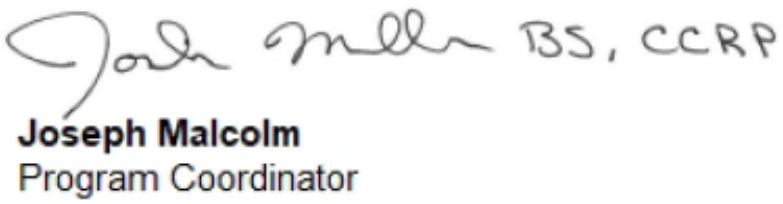




\section{Isabella H. McDaniel}

(304) 222-5652

Email: $\underline{\text { hmmcdaniel@mix.wvu.edu }}$

\section{Education}

BS, West Virginia University, 2018.

Major: Dental Hygiene

MS, West Virginia University, August 2018 - Present

Major: Dental Hygiene

\section{Licensure and Certifications}

Cardiopulmonary Resuscitation Certification, American Heart Association. (February 2020- Present)

West Virginia In-Office Bleaching Permit, West Virginia Board of Dental Examiners. (May 2018)

West Virginia Local Anesthesia for Dental Hygienists' Certificate, West Virginia Board of Dental Examiners. (May 2018)

West Virginia Dental Hygiene License, West Virginia Board of Dental examiners. (May 2018)

\section{Public Service}

Volunteer, Alzheimer's Association's Walk to End Alzheimer's, Morgantown, West Virginia. (September 9, 2014)

Volunteer, Chi Alpha Student Christian Ministry's Trunk-or-Treat, Morgantown, West Virginia. (October 30, 2014)

Volunteer, Gap Inc. Ronald McDonald House, Morgantown, West Virginia. (November $13,2014)$ 
Volunteer, American Cancer Association's Relay for Life, Morgantown, West Virginia. (April 24, 2015)

Volunteer, The Habitat of Humanity's Bicycle Rave, Upper Glade, West Virginia. (June $6,2015)$

Volunteer, Chi Alpha Student Christian Ministry’s Mission Trip, Fairbanks, Alaska. (March 22, 2015)

Volunteer, Student American Dental Hygiene Association's Trunk-or-Treat, Morgantown, West Virginia. (October 19, 2015)

Volunteer, American Caner Association's Relay for Life, Morgantown, West Virginia. (April 22, 2016)

Volunteer, Salvation Army, West Virginia. (October 12, 2016)

Volunteer, Rosenbaum House Dinner, Morgantown, West Virginia. (January 1, 2017)

Volunteer, Student American Dental Hygiene Association's formal decorations, West Virginia. (April 11, 2017)

Volunteer, West Virginia’s Special Olympic, Charleston, West Virginia. (July 13, 2017) 